\title{
Diet quality from pre-school to school age in Brazilian children: a 4-year follow-up in a randomised control study
}

\author{
Fernanda Rauber ${ }^{1 *}$, Daniel J. Hoffman ${ }^{2}$ and Márcia Regina Vitolo ${ }^{3}$ \\ ${ }^{1}$ Graduate Program in Health Sciences, Universidade Federal de Ciencias da Saude de Porto Alegre, \\ 245 Sarmento Leite, Porto Alegre 90050-170, Brazil \\ ${ }^{2}$ Department of Nutritional Sciences, School of Environmental and Biological Sciences, Rutgers, \\ The State University of New Jersey, New Brunswick, NJ, USA \\ ${ }^{3}$ Department of Nutrition, Universidade Federal de Ciencias da Saude de Porto Alegre, 245 Sarmento Leite, \\ Porto Alegre 90050-170, Brazil \\ (Submitted 18 April 2013 - Final revision received 23 July 2013 - Accepted 25 July 2013 - First published online 21 August 2013 )
}

\section{Abstract}

A previous study demonstrated that dietary counselling for mothers during the first year of life improved overall diet quality of children at pre-school age in a low-income population. Thus, the objective of the present study was to assess the long-term effect of this intervention on diet quality of children at school age and examine the tracking of dietary intake throughout childhood. The present study was a followup of a randomised controlled trial with children who were assessed at 3-4 years ( $n$ 345) and 7-8 years ( $n$ 307) of age. We collected two $24 \mathrm{~h}$ dietary recalls and assessed diet quality using the Healthy Eating Index (HEI). Analyses were performed by group using a paired $t$ test and a Student's $t$ test for independent samples. Diet quality did not differ between the intervention and control groups at $7-8$ years of age (HEI score 65.2 (SD 9.5) v. 64.9 (SD 8.5)). Regarding changes in diet quality from pre-school to school age, we observed the tracking of diet quality in the control group and the loss of the intervention effect in the intervention group. In both groups, the score for fruit and milk intake decreased, while that for saturated fat and dietary variety intake increased. The score for the intakes of grains, meat and legumes, and total fat remained constant for all children. The present data provide evidence that diet quality tracks during childhood since the total HEI score did not differ over time in the control group. The decrease in score for some HEI components did not affect the overall diet quality due to the increase in score for other HEI components.

Key words: Children: Diet: Longitudinal studies

Dietary patterns have been changing rapidly in recent decades and are characterised by a decreased consumption of fruit and vegetables and an increased consumption of processed foods that are high in sugar, saturated fat and $\mathrm{Na}$ and low in fibre ${ }^{(1-6)}$. Such dietary patterns may be partially responsible for the increased prevalence of obesity ${ }^{(7-11)}$, especially for children and adolescents ${ }^{(12-14)}$. More important is the fact that childhood obesity tends to track into adult life, leading to an increased prevalence of chronic diseases and early mortality ${ }^{(15,16)}$.

Many children consume diets that do not meet current recommendations for foods or nutrients ${ }^{(17-19)}$. In Brazil, almost $65 \%$ of children need to improve the quality of their diet ${ }^{(20)}$, a finding that is especially alarming, considering that dietary patterns in childhood may track into adulthood ${ }^{(21)}$. However, only one of these studies focused on pre-school children ${ }^{(22)}$.
During the first year of life, the introduction of solid foods is an important developmental milestone because it may affect the acceptance of foods in infancy and possibly food preferences in later life ${ }^{(23-25)}$. Although most children can rank order their preferences during early childhood ${ }^{(26)}$, evidence suggests that the pre-school child's diet may be affected by maternal and family characteristics ${ }^{(27,28)}$. In the primary grades, children become more independent and influenced by outside sources, such as the school environment, peers and marketing of foods, that affect their eating behaviours $^{(29,30)}$.

We aimed to determine the developmental changes in diet quality, using longitudinal data from a sample of pre-school (3-4 years) and school ( $7-8$ years) children and to assess whether or not food group and nutrient intakes track during childhood. Previous studies of this cohort have shown a positive impact of maternal dietary counselling during the first

Abbreviation: HEI, Healthy Eating Index.

*Corresponding author: F. Rauber, fax +55 51 33038798, email rauber.fernanda@gmail.com 
year of life on feeding practices at infant age ${ }^{(31)}$ and on diet quality at pre-school age, as assessed using the Healthy Eating Index $(\mathrm{HEI})^{(32)}$. Therefore, we also assessed the impact of maternal dietary counselling during the first year of life on the diet quality of school-age children (longterm effect)

\section{Methods}

The present study was a data analysis of children who participated in a randomised trial of dietary counselling on breast-feeding and dietary practices during the first year of life ${ }^{(31)}$. A total of 500 mother-child pairs were recruited between October 2001 and June 2002 in the maternity ward of a hospital that attends to a low-income population, in São Leopoldo, Brazil, and the same children have been followed since. Inclusion criteria were full-term ( $>37$ weeks) babies with a birth weight $\geq 2500 \mathrm{~g}$. Exclusion criteria were HIV-positive mothers, congenital malformations and children admitted to the intensive care unit. The present study was conducted according to the guidelines laid down in the Declaration of Helsinki, and all procedures involving human subjects were approved by the Ethics Committee of the Universidade Federal de Ciencias da Saude de Porto Alegre. Written informed consent was obtained from all mothers.

\section{Data collection}

Fieldworkers conducted face-to-face structured interviews during home visits with the mothers at 6 months, 3-4 and 7-8 years following birth. Data were authenticated at monthly intervals by randomly calling $10 \%$ of the households and repeating several questions in the survey. Identification and data required for locating the family in the community were collected at the time of recruitment. Sex and data of birth were obtained from hospital records. Socio-economic characteristics, such as maternal education and family income, were assessed when the children reached an age of 6 months by face-to-face interviews with the mothers. At 3-4 and 7-8 years of age, two $24 \mathrm{~h}$ dietary recalls for each child were collected on two non-consecutive days and mean values were used in the analyses. For children aged 3-4 years, the recall was provided by the mothers or other caregivers; recalls of 7-8 years old were self-reported with assistance from the mothers or other caregivers. To quantify food portion size, pictures were used to illustrate standard household measurements, such as teaspoons, tablespoons, and cups. Dietary information was entered in the NutWin program (version 1.5; Federal University of São Paulo) to support nutrition in order to estimate energy and nutrient intake. Data collection and analyses did not include salt added during cooking and/or at the table, or the ingestion of pure water.

\section{Diet quality assessment}

Diet quality was determined using the HEI, an instrument that attributes scores to the diets of individuals based on dietary recommendations and takes into consideration the imbalance between components of humans' diets and non-isolated nutrient ${ }^{(33)}$. The HEI is the sum of ten components, each representing different aspects of a healthful diet, and the recommendations depend on the energy requirements according to age group ${ }^{(33)}$. The first five components of the index are food groups based on the Food Guide Pyramid (US Department of Agriculture): grains, fruit, vegetables, and meat and milk. Intakes at or above the recommended amounts were awarded a full score of 10 points, whereas intermediate numbers of servings were scored proportionally. For components six to nine, a full score of 10 points each was awarded for diets with up to $30 \%$ of energy from fat, $10 \%$ of energy from saturated fat, $300 \mathrm{mg} / \mathrm{d}$ of cholesterol and $1500 \mathrm{mg} / \mathrm{d}$ of $\mathrm{Na}$. To assess the tenth component of the HEI score, dietary variety was calculated by counting the total number of different foods and food groups consumed, considering only those that contributed at least one-half of a serving from any of the food groups. A maximum score was given if eight or more different food items were consumed per $\mathrm{d}$, whereas a score of zero was given if three or fewer different items were eaten. Intermediate intakes were calculated proportionally. Similar foods, such as mashed and baked potatoes, were considered as one item towards dietary variety, and mixed foods were broken down into their ingredients.

Each of the ten components ranged in score from 0 to 10. Thus, the composite HEI score can potentially range from a minimum score of 0 to a maximum score of 100. A total score of more than 80 was considered 'good', scores of 51-80 indicated 'needs improvement' and scores less than 51 were considered 'poor' ${ }^{\text {(33). }}$.

Some modifications in the food classification according to the HEI components were carried out in order to meet the Brazilian dietary guideline recommendations ${ }^{(34,35)}$. Potatoes and other related root vegetables were included in the grains group instead of the vegetables group, as they are considered a 'starchy food'; beans and lentils were included in the meat group only (using lean meat ounce equivalents) and not in the vegetables group; fried food, processed meat products (e.g. sausages, ham, salami), candied foods and sweets were not included in any of the first five food groups because of their high fat and sugar content.

\section{Statistical analyses}

All statistical analyses were performed using SPSS 16.0 (SPSS, Inc.). Non-normally distributed variables were logtransformed (components: total fat, saturated fat, cholesterol and $\mathrm{Na}$ ). Despite the use of log-transformed variables in the analyses, untransformed values were presented in tables for clinical interpretation. The effect of the intervention on the mean HEI score at 7-8 years of age was evaluated by Student's $t$ test for independent samples (particularly the mean HEI score and its components for both the intervention and control groups). To determine dietary changes, analyses were performed by group (intervention and control) since a previous study ${ }^{(31)}$ with this same sample of children demonstrated a positive impact on diet quality at 3-4 years of age in the intervention group. To study the changes in food 
groups, we computed mean servings per d for each food group and time point. To determine the changes in diet quality, we computed the HEI score (total and each component) that considers the recommendations for each age. HEI scores were similar for boys and girls, therefore analyses were carried out on both sexes together. Analyses of time effects (i.e. changes in diet intake at 3-4 and 7-8 years of age) were conducted using a paired $t$ test. McNemar's test with the continuity correction was used to analyse the changes in prevalence. Data are expressed as mean differences and 95\% CI. Statistical significance was set at $P<0 \cdot 05$.

Comparisons in terms of race, sex, weight at birth, length at birth, maternal age at child's birth, maternal education level and annual family income between children who were lost to follow-up and those who remained were made using the $\chi^{2}$ and Student's $t$ test or Mann-Whitney $U$ test, as appropriate.

\section{Results}

\section{Sample characteristics}

Among the 500 initially recruited children at birth, 356 children at 3-4 years of age and 315 children at 7-8 years of age were assessed. The causes of loss to follow-up were refusal to continue ( $n$ 31), non-localised address ( $n$ 148), child or maternal death ( $n$ 3) and genetic disease ( $n$ 3). No difference was found regarding race, sex, weight at birth, length at birth, maternal age at child's birth, maternal education level and annual family income between children who were lost to follow-up and those who remained at 7-8 years of age. The number of children who presented complete dietary data was 345 children at 3-4 years of age, 307 at $7-8$ years of age and 289 at both time points. No difference was found in terms of total HEI scores and HEI scores for each component between children with dietary data at both time points $(n$ 289) and those with dietary data at just one time point (3-4 or $7-8$ years).
Over half of the children were male $(57 \cdot 1 \%)$ and non-white (57\%). The annual household income per capita varied from $\mathrm{R} \$ 180.00$ to $\mathrm{R} \$ 11100 \cdot 00$ (US $\$ 83.33$ to $\$ 5138.88$ ), $\mathrm{R} \$ 2559 \cdot 70$ (SD 1781.50) on average (US $\$ 1185 \cdot 04$ (SD 824.76)), whereas the maternal education level varied from 1 to 13 years of schooling (6.9 (SD 2.7)).

No difference was found between the intervention and control groups regarding the score of the total HEI (65.2 (SD 9.5) $v$. 64.9 (SD 8.5), $P=0.36$ ) and of each HEI component among children at $7-8$ years of age $(P>0 \cdot 05)$.

\section{Recommendation and intake (servings or amounts)}

In both the intervention and control groups, the mean intakes (servings/d) of grains, meat and legumes, vegetables, fruit and dietary variety (different foods/d) were below the recommended level, while the mean intakes of total fat (percentage of energy), cholesterol $(\mathrm{mg} / \mathrm{d})$ and $\mathrm{Na}(\mathrm{mg} / \mathrm{d})$ were within the recommended level at both time points. The mean intake was within and below the recommended level of milk (servings/d), at 3-4 and 7-8 years of age, respectively (Table 1 ).

In both the intervention and control groups, less than $10 \%$ of the children met the recommendation for the intakes of grains and vegetables at each time point and the percentage of the children who met the recommendation for the intakes of meat and legumes, and fruit and milk was significantly lower at 7-8 years of age. Cholesterol was the only component for which more than $80 \%$ of the children achieved the recommended level (Table 2).

\section{Trends in diet quality (Healthy Eating Index score)}

In the control group, $93.5 \%$ of the children at 3-4 years of age and $96 \%$ of the children at $7-8$ years of age had diets that were poor or needed improvement. Diet quality, as assessed using the HEI score, tracked over time. In the intervention group, $86 \cdot 2 \%$ of the children at 3-4 years of age and $94.7 \%$

Table 1. Dietary recommendation* and mean intakes of the components of the Healthy Eating Index at 3-4 and 7-8 years of age, in São Leopoldo, Brazil (Mean values and standard deviations)

\begin{tabular}{|c|c|c|c|c|c|c|c|c|c|c|}
\hline & & & \multicolumn{8}{|c|}{ Intake } \\
\hline & & & & Inten & tion & & & & & \\
\hline & \multicolumn{2}{|c|}{ Recommendation* } & \multicolumn{2}{|c|}{$\begin{array}{c}3-4 \text { years } \\
(n 145)\end{array}$} & \multicolumn{2}{|c|}{$\begin{array}{c}7-8 \text { years } \\
(n 131)\end{array}$} & \multicolumn{2}{|c|}{$\begin{array}{c}3-4 \text { years } \\
(n 200)\end{array}$} & \multicolumn{2}{|c|}{$\begin{array}{c}7-8 \text { years } \\
(n 176)\end{array}$} \\
\hline & $3-4$ years & $7-8$ years & Mean & SD & Mean & SD & Mean & SD & Mean & SD \\
\hline Grains (servings/d) & 6 & $7 \cdot 8$ & $3 \cdot 0$ & 1.5 & $4 \cdot 1$ & 1.5 & $3 \cdot 1$ & 1.5 & $3 \cdot 8$ & $1 \cdot 1$ \\
\hline Meat and legumes (servings/d) & 2 & $2 \cdot 3$ & $1 \cdot 3$ & 0.8 & 1.4 & 0.8 & 1.3 & 0.8 & $1 \cdot 3$ & 0.7 \\
\hline Vegetables (servings/d) & 2 & $2 \cdot 7$ & 0.4 & 0.6 & 0.5 & 0.4 & 0.3 & 0.7 & 0.5 & 0.4 \\
\hline Fruit (servings/d) & 3 & $3 \cdot 7$ & 1.0 & 0.9 & 0.7 & 0.7 & 0.7 & 0.8 & 0.7 & 0.8 \\
\hline Milk (servings/d) & 2 & 2 & $3 \cdot 1$ & 1.7 & 1.7 & 1.0 & $3 \cdot 1$ & $1 \cdot 8$ & 1.7 & $1 \cdot 1$ \\
\hline Total fat (\% energy) & $\leq 30$ & $\leq 30$ & $28 \cdot 0$ & $5 \cdot 1$ & $28 \cdot 9$ & 4.5 & 28.4 & $5 \cdot 2$ & $28 \cdot 3$ & 4.9 \\
\hline Saturated fat (\% energy) & $\leq 10$ & $\leq 10$ & $10 \cdot 6$ & $3 \cdot 1$ & 8.7 & $2 \cdot 1$ & $10 \cdot 8$ & $3 \cdot 2$ & 8.5 & $2 \cdot 2$ \\
\hline Cholesterol $(\mathrm{mg} / \mathrm{d})$ & $<300$ & $<300$ & 186 & 102 & 150 & 66 & 166 & 85 & 154 & 85 \\
\hline $\mathrm{Na}(\mathrm{mg} / \mathrm{d})$ & $\leq 1500$ & $\leq 1500$ & 1203 & 679 & 1595 & 718 & 1326 & 733 & 1456 & 582 \\
\hline Dietary variety $\dagger$ & $\geq 8$ & $\geq 8$ & 6.9 & $1 \cdot 8$ & 7.4 & $1 \cdot 7$ & $6 \cdot 3$ & 1.9 & $7 \cdot 1$ & $1 \cdot 6$ \\
\hline
\end{tabular}

${ }^{\star}$ Basiotis et al. ${ }^{(36)}$.

† Number of different foods per $\mathrm{d}$. 
Table 2. Percentage of children meeting the recommendation from each component of the Healthy Eating Indext, in São Leopoldo, Brazil

(Number of participants and percentages)

\begin{tabular}{|c|c|c|c|c|}
\hline & \multicolumn{2}{|c|}{$3-4$ years } & \multicolumn{2}{|c|}{$7-8$ years } \\
\hline & $n$ & $\%$ & $n$ & $\%$ \\
\hline \multicolumn{5}{|l|}{ Intervention group } \\
\hline Grains & 5 & 3.4 & 3 & $2 \cdot 3$ \\
\hline Meat and legumes & 36 & 24.8 & 15 & $11.5^{\star \star}$ \\
\hline Vegetables & 2 & 1.4 & 0 & 0 \\
\hline Fruit & 23 & $15 \cdot 9$ & 3 & $2 \cdot 3^{\star \star}$ \\
\hline Milk & 111 & $76 \cdot 6$ & 56 & $42 \cdot 7^{\star \star}$ \\
\hline Total fat & 100 & $69 \cdot 0$ & 80 & $61 \cdot 1$ \\
\hline Saturated fat & 64 & $44 \cdot 0$ & 96 & $73 \cdot 3^{\star \star}$ \\
\hline Cholesterol & 125 & $86 \cdot 2$ & 126 & $96 \cdot 2^{*}$ \\
\hline $\mathrm{Na}$ & 108 & 74.5 & 70 & $53 \cdot 4^{\star \star}$ \\
\hline Dietary variety & 44 & $30 \cdot 3$ & 57 & $43 \cdot 5^{\star \star}$ \\
\hline \multicolumn{5}{|l|}{ Control group } \\
\hline Grains & 12 & $6 \cdot 0$ & 0 & $0^{\star \star}$ \\
\hline Meat and legumes & 46 & 23.0 & 14 & $8.0^{* *}$ \\
\hline Vegetables & 3 & 1.5 & 0 & 0 \\
\hline Fruit & 21 & $10 \cdot 5$ & 5 & $2 \cdot 8^{\star \star}$ \\
\hline Milk & 139 & 69.5 & 77 & $43 \cdot 8^{\star \star}$ \\
\hline Total fat & 129 & 64.5 & 109 & 61.9 \\
\hline Saturated fat & 82 & 41.0 & 129 & $73 \cdot 3^{\star \star}$ \\
\hline Cholesterol & 188 & 94.0 & 168 & 95.5 \\
\hline $\mathrm{Na}$ & 137 & 68.5 & 103 & 58.5 \\
\hline Dietary variety & 47 & 23.5 & 62 & $35 \cdot 2^{\star \star}$ \\
\hline
\end{tabular}

Value was significantly different from that for the same group at 3-4 years of age: ${ }^{*} P<0.05,{ }^{* *} P<0.01$.

†Children who achieved the maximum score for the component (score $=10)$.

of the children at 7-8 years of age had diets that were poor or needed improvement. The changes in diet quality over time illustrate the loss of the intervention effect at 7-8 years of age (Table 3 ).

In both groups, the score for the intake of fruit and milk decreased over time, while the score for the intake of saturated fat and dietary variety increased. The children maintained their score for the intakes of grains, meat and legumes, and total fat over time in both groups (Table 4).

\section{Discussion}

Understanding whether children's dietary quality changes or whether their eating patterns and dietary quality remain stable during middle childhood may allow for targeted intervention efforts to promote healthy diets and improve nutrient intake in early life and throughout childhood. The present results showed that the children did not meet the HEI-2000 recommendations ${ }^{(36)}$ for most of the food groups studied at either pre-school or school age. These results are consistent with other findings ${ }^{(37-40)}$, suggesting that children's dietary intake constitutes a risk factor for nutritional deficiencies, obesity and chronic diseases in both developed and developing countries.

In the present study, we highlight two major findings. The first major finding is that the positive effect that maternal dietary counselling during the first year of life had on diet quality at 3-4 years of age ${ }^{(32)}$ was lost at 7-8 years of age. These data may be explained by the intervention's lack of long-term effect, which may be related to older children's increased autonomy regarding their food choices. School children have many opportunities to eat without parental supervision and can more easily access foods in their social environments $^{(41)}$. Although studies have emphasised the importance of promoting health during early childhood ${ }^{(42,43)}$, training older children in self-regulatory skills regarding their food choices and conducting interventions that penetrate school settings may be of equal importance, maintaining healthy eating habits throughout one's life.

The second major finding is that diet quality tracks during childhood since the total HEI score did not change from pre-school to school age in the control group. While there is some evidence showing moderate to strong tracking for nutrient intakes among children ${ }^{(44-46)}$, eating patterns may change gradually during childhood ${ }^{(47)}$ and children's diets tend to decline in quality as they get older ${ }^{(48,49)}$. We found that the decrease in score for some HEI components did not affect the overall diet quality due to the increase in score for other HEI components. The decrease in the intake of fruit and milk is consistent with other studies ${ }^{(49,50)}$ and may reflect the fact that, as children get older, they have more autonomy in making food choices ${ }^{(29,30)}$ and their environment offers them more unhealthy food choices ${ }^{(51)}$. Low intakes of meat, grains and vegetables at pre-school age continued during school age. Foods from these groups, which comprise part of the traditional Brazilian diet (such as rice and beans), have been replaced by processed products ${ }^{(1,6)}$. Among nutrients, the reduced saturated fat consumption can be explained by the lower milk intake observed in the present study. Although we found that fat intake was appropriate, studies have shown an increase in the consumption of processed foods, which are high in fat and very available and accessible to children $^{(5,51)}$.

Table 3. Dietary quality of children at $3-4$ and $7-8$ years of age evaluated using the Healthy Eating Index (HEI), in São Leopoldo, Brazil (Mean values and standard deviations or percentages; mean differences and $95 \%$ confidence intervals)

\begin{tabular}{|c|c|c|c|c|}
\hline & $\begin{array}{c}3-4 \\
\text { years }\end{array}$ & $\begin{array}{c}7-8 \\
\text { years }\end{array}$ & $\begin{array}{c}\text { Mean } \\
\text { difference }\end{array}$ & $\begin{array}{c}95 \% \\
\mathrm{Cl}\end{array}$ \\
\hline \multicolumn{5}{|l|}{ Intervention group } \\
\hline \multicolumn{5}{|l|}{ Total HEI score } \\
\hline Mean & $68 \cdot 2$ & $65 \cdot 1$ & $-3 \cdot 0^{*}$ & $-5 \cdot 6,-0.5$ \\
\hline SD & $10 \cdot 2$ & 9.4 & & \\
\hline Good¥ (\%) & $13 \cdot 8$ & $5 \cdot 3$ & & \\
\hline $\begin{array}{l}\text { Needs } \\
\quad \text { improvement§ (\%) }\end{array}$ & $80 \cdot 7$ & $86 \cdot 3$ & & \\
\hline Poor\| (\%) & $5 \cdot 5$ & $8 \cdot 4$ & & \\
\hline \multicolumn{5}{|l|}{ Control group } \\
\hline \multicolumn{5}{|l|}{ Total HEI score $\dagger$} \\
\hline Mean & $63 \cdot 8$ & 64.9 & $1 \cdot 1$ & $-1 \cdot 0,3 \cdot 3$ \\
\hline SD & 11.4 & $8 \cdot 3$ & & \\
\hline Good $\ddagger$ (\%) & 6.5 & 4.0 & & \\
\hline $\begin{array}{l}\text { Needs } \\
\quad \text { improvement§ (\%) }\end{array}$ & 79 & $90 \cdot 3$ & & \\
\hline Poor\| (\%) & 14.5 & $5 \cdot 7$ & & \\
\hline
\end{tabular}

${ }^{*}$ There was a significant difference between the age groups $(P<0.05)$.

$\dagger$ The total $\mathrm{HEI}$ score ranges from 0 to 100 .

$\ddagger$ Score $>80$.

$\S$ Score $51-80$

|| Score $<51$. 
Table 4. Mean difference in score from each component of the Healthy Eating Index at 3-4 and 7-8 years of age, in São Leopoldo, Brazil

(Mean values and standard deviations; mean differences and $95 \%$ confidence intervals)

\begin{tabular}{|c|c|c|c|c|c|c|c|}
\hline & \multicolumn{2}{|c|}{$3-4$ years $\dagger$} & \multicolumn{2}{|c|}{$7-8$ years $†$} & \multirow{2}{*}{$\begin{array}{c}\text { Mean } \\
\text { difference }\end{array}$} & \multirow[b]{2}{*}{$95 \% \mathrm{Cl}$} & \multirow{2}{*}{$\begin{array}{c}\text { Percentage } \\
\text { change }\end{array}$} \\
\hline & Mean & SD & Mean & SD & & & \\
\hline \multicolumn{8}{|l|}{ Intervention group } \\
\hline Grains & $5 \cdot 1$ & $2 \cdot 1$ & $5 \cdot 2$ & $1 \cdot 7$ & 0.1 & $-0.2,0.5$ & 1.9 \\
\hline Meat and legumes & $6 \cdot 2$ & $2 \cdot 9$ & $5 \cdot 9$ & $2 \cdot 7$ & -0.3 & $-0.9,0.3$ & $-4 \cdot 8$ \\
\hline Vegetables & 1.5 & $2 \cdot 0$ & 1.4 & 1.3 & -0.1 & $-0.5,0.2$ & -6.6 \\
\hline Fruit & 4.4 & 3.4 & $2 \cdot 6$ & $2 \cdot 4$ & $-1 \cdot 7^{\star}$ & $-2 \cdot 5,-1 \cdot 0$ & $-40 \cdot 9$ \\
\hline Milk & $9 \cdot 1$ & $2 \cdot 0$ & $7 \cdot 2$ & $3 \cdot 1$ & $-1 \cdot 8^{*}$ & $-2 \cdot 4,-1 \cdot 2$ & $-20 \cdot 8$ \\
\hline Total fat§ & $9 \cdot 2$ & 1.5 & $9 \cdot 0$ & $1 \cdot 7$ & -0.2 & $-0.6,0.1$ & $-2 \cdot 1$ \\
\hline Saturated fat§ & $7 \cdot 1$ & 3.5 & $9 \cdot 2$ & $1 \cdot 7$ & $2 \cdot 0^{*}$ & $1 \cdot 3,2 \cdot 6$ & 29.5 \\
\hline Cholesterol§ & 9.4 & 1.9 & $9 \cdot 8$ & 0.8 & $0.4^{*}$ & $0.03,0.8$ & 4.2 \\
\hline $\mathrm{Na \S}$ & $8 \cdot 6$ & $3 \cdot 2$ & $6 \cdot 4$ & 4.3 & $-2 \cdot 2^{*}$ & $-3 \cdot 1,-1 \cdot 3$ & -25.5 \\
\hline Dietary variety & $7 \cdot 2$ & $2 \cdot 6$ & $8 \cdot 0$ & $2 \cdot 5$ & $0.8^{*}$ & $0.2,1.4$ & $11 \cdot 1$ \\
\hline \multicolumn{8}{|l|}{ Control group } \\
\hline Grains & $5 \cdot 0$ & $2 \cdot 3$ & 4.9 & 1.4 & -0.1 & $-0.4,0.2$ & $-2 \cdot 0$ \\
\hline Meat and legumes & $6 \cdot 0$ & $2 \cdot 9$ & $5 \cdot 7$ & $2 \cdot 7$ & -0.3 & $-0.9,0.1$ & $-5 \cdot 0$ \\
\hline Vegetables & 0.9 & 1.7 & $1 \cdot 3$ & 1.3 & $0.4^{*}$ & $0.1,0.7$ & 44.4 \\
\hline Fruit & $3 \cdot 6$ & $3 \cdot 8$ & $2 \cdot 6$ & $2 \cdot 7$ & $-0.9^{*}$ & $-1.6,-0.3$ & $-27 \cdot 7$ \\
\hline Milk & 8.5 & 2.5 & $7 \cdot 1$ & $3 \cdot 3$ & $-1.4^{\star}$ & $-2 \cdot 0,-0.9$ & $-16 \cdot 4$ \\
\hline Total fat§ & $9 \cdot 0$ & 1.9 & $9 \cdot 2$ & $1 \cdot 3$ & $0 \cdot 2$ & $-0.08,0.5$ & $2 \cdot 2$ \\
\hline Saturated fat§ & $6 \cdot 8$ & 3.6 & 9.4 & $1 \cdot 3$ & $2 \cdot 5^{\star}$ & $2 \cdot 0,3 \cdot 1$ & $38 \cdot 2$ \\
\hline Cholesterol§ & $9 \cdot 7$ & $1 \cdot 3$ & $9 \cdot 7$ & 1.4 & 0.01 & $-0.2,0.3$ & 0 \\
\hline $\mathrm{Na \S}$ & $7 \cdot 6$ & 3.9 & $7 \cdot 1$ & 4.0 & -0.5 & $-1 \cdot 3,0.2$ & -6.5 \\
\hline Dietary variety & $6 \cdot 2$ & 2.9 & 7.5 & $2 \cdot 5$ & $1 \cdot 3^{\star}$ & $0.8,1 \cdot 8$ & $20 \cdot 9$ \\
\hline
\end{tabular}

* There was a significant difference between the age groups $(P<0.05)$.

† Each component ranges from 0 to 10 .

$\ddagger((7-8$ years $)-(3-4$ years $)) / 3-4$ years.

$\S$ Variables that were log-transformed for the analysis.

Regarding $\mathrm{Na}$ intake, the dietary recall did not include the salt used in food preparation due to a lack of data on added salt. Although an estimate based on a Brazilian household budget survey showed that most of the Na available for family consumption was from table salt and salt-based condiments $^{(52)}$, a national survey has demonstrated a major increase in the intakes of ultra-processed foods (breads, cookies, sweets, soft drinks, sausages, cheeses, cold cuts and canned foods) by the Brazilian population in the past 30 years ${ }^{(5)}$. We believe that the main source of $\mathrm{Na}$ consumed by the children in the present study came from ultra-processed foods, which is consistent with other studies ${ }^{(53,54)}$.

Several potential limitations should be discussed to fully appreciate the present results. First, longitudinal studies are prone to subject to loss during follow-up. However, we did not observe any differences between the basic characteristics of the children who remained in the study and those who were lost to follow-up. Second, the present results cannot be generalised to large populations as we only included children from low-income families. Third, the children's dietary data were reported by the mothers and children (at 7-8 years of age) and are subject to reporting errors. However, we used the multiple-pass method to facilitate dietary recall and reduce error. Fourth, intra-individual intake variation does vary by nutrient and food group, which could attenuate the statistical significance of mean estimates. Since we used the average intake of $2 \mathrm{~d}$ in both dietary assessments to compare the dietary data of each child, we believed that such an error was mitigated and less likely to affect our conclusion. Finally, the HEI score was calculated using the 2000 version instead of the 2005 version. We chose not to use the 2005 version because it emphasises certain food groups (such as whole grains, nuts and seeds) that are not often consumed by children in Brazil. Despite this issue, we have confidence in the present results since the same version of the HEI was used for the two assessed age groups. In addition, studies have demonstrated associations of the original version of the HEI with plasma nutrient concentrations ${ }^{(55,56)}$ and its applicability in assessing children's $\operatorname{diets}^{(40)}$, validating it as a useful tool for overall descriptions of diet. The present study has strengths that reinforce our findings. The longitudinal design allows for the assessment of children's dietary quality changes over time as well as consumption changes among the food and nutrient groups. Also, data collection was done in the same way for the two assessed age groups, as was the recording and calculation of dietary data, enabling the data to be compared.

\section{Conclusions/future research}

The present study found that diet quality tracks from pre-school to school age in the control group, suggesting that dietary habits are established early in life and track during childhood. Intervention programmes and actions to promote healthy eating and improve nutrient intake should begin early in life and continue throughout childhood since maternal dietary counselling during the first year of life was effective in promoting better diet quality at pre-school age $^{(32)}$, though not at school age. Childhood dietary patterns may be an important factor in the development of food 
habits later in life. We therefore intend to assess the diet quality of this same sample of children when they enter adolescence (12-13 years old).

\section{Acknowledgements}

The present study was supported by the Brazil CNPq (National Funding for Research) and CAPES Foundation, Ministry of Education (doctoral fellowship to F. R., process no. 9853-11-1). CNPq and CAPES had no role in the design, analysis or writing of this article.

The authors' contributions are as follows: F. R. contributed to the data analyses, the interpretation of the results, and the drafting and critical revision of the manuscript; D. J. H. contributed to the drafting and critical revision of the manuscript; M. R. V. contributed to the research proposal, the interpretation of the results, and the drafting and critical revision of the manuscript.

The authors declare that they have no conflicts of interest.

\section{References}

1. Levy-Costa RB, Sichieri R, Pontes Ndos S, et al. (2005) [Household food availability in Brazil: distribution and trends (1974-2003)]. Rev Saude Publica 39, 530-540.

2. Guenther PM, Dodd KW, Reedy J, et al. (2006) Most Americans eat much less than recommended amounts of fruits and vegetables. J Am Diet Assoc 106, 1371-1379.

3. Bachman JL, Reedy J, Subar AF, et al. (2008) Sources of food group intakes among the US population, 2001-2002. J Am Diet Assoc 108, 804-814.

4. Piernas C \& Popkin BM (2010) Snacking increased among U.S. adults between 1977 and 2006. J Nutr 140, 325-332.

5. Monteiro CA, Levy RB, Claro RM, et al. (2011) Increasing consumption of ultra-processed foods and likely impact on human health: evidence from Brazil. Public Health Nutr 14, 5-13.

6. Levy RB, Claro RM, Mondini L, et al. (2012) Regional and socioeconomic distribution of household food availability in Brazil, in 2008-2009. Rev Saude Publica 46, 6-15.

7. Heo M, Kim RS, Wylie-Rosett J, et al. (2011) Inverse association between fruit and vegetable intake and BMI even after controlling for demographic, socioeconomic and lifestyle factors. Obes Facts 4, 449-455.

8. World Health Organization (2013) Obesity and Overweight. Fact Sheet no. 311. Geneva: WHO. http://www.who.int/ mediacentre/factsheets/fs311/en/\# (accessed August 2012).

9. Astrup A, Dyerberg J, Selleck M, et al. (2008) Nutrition transition and its relationship to the development of obesity and related chronic diseases. Obes Rev 9, Suppl. 1, 48-52.

10. Batista Filho M, Souza AI, Miglioli TC, et al. (2008) [Anemia and obesity: a paradox of the nutritional transition in Brazil]. Cad Saude Publica 24, Suppl. 2, S247-S257.

11. Popkin BM (2011) Contemporary nutritional transition: determinants of diet and its impact on body composition. Proc Nutr Soc 70, 82-91.

12. Rolls BJ (2009) The relationship between dietary energy density and energy intake. Physiol Behav 97, 609-615.

13. Vernarelli JA, Mitchell DC, Hartman TJ, et al. (2011) Dietary energy density is associated with body weight status and vegetable intake in U.S. children. J Nutr 141, 2204-2210.

14. Corvalan C, Kain J, Weisstaub G, et al. (2009) Impact of growth patterns and early diet on obesity and cardiovascular risk factors in young children from developing countries. Proc Nutr Soc 68, 327-337.

15. Singh AS, Mulder C, Twisk JW, et al. (2008) Tracking of childhood overweight into adulthood: a systematic review of the literature. Obes Rev 9, 474-488.

16. Gardner DS, Hosking J, Metcalf BS, et al. (2009) Contribution of early weight gain to childhood overweight and metabolic health: a longitudinal study (EarlyBird 36). Pediatrics 123, e67-e73.

17. Fox MK, Condon E, Briefel RR, et al. (2010) Food consumption patterns of young preschoolers: are they starting off on the right path? J Am Diet Assoc 110, S52-S59.

18. Johnson-Down L \& Egeland GM (2010) Adequate nutrient intakes are associated with traditional food consumption in nunavut inuit children aged $3-5$ years. J Nutr 140, $1311-1316$

19. Golley RK, Hendrie GA \& McNaughton SA (2011) Scores on the dietary guideline index for children and adolescents are associated with nutrient intake and socio-economic position but not adiposity. J Nutr 141, 1340-1347.

20. Molina Mdel C, Lopez PM, Faria CP, et al. (2010) Socioeconomic predictors of child diet quality. Rev Saude Publica 44, 785-732.

21. Craigie AM, Lake AA, Kelly SA, et al. (2011) Tracking of obesity-related behaviours from childhood to adulthood: a systematic review. Maturitas 70, 266-284

22. Mikkila V, Rasanen L, Raitakari OT, et al. (2005) Consistent dietary patterns identified from childhood to adulthood: the cardiovascular risk in Young Finns Study. Br J Nutr 93, 923-931.

23. Skinner JD, Carruth BR, Wendy B, et al. (2002) Children's food preferences: a longitudinal analysis. J Am Diet Assoc 102, 1638-1647.

24. Coulthard H, Harris G \& Emmett P (2009) Delayed introduction of lumpy foods to children during the complementary feeding period affects child's food acceptance and feeding at 7 years of age. Matern Child Nutr 5, 75-85.

25. Mennella JA \& Trabulsi JC (2012) Complementary foods and flavor experiences: setting the foundation. Ann Nutr Metab 60, Suppl. 2, 40-50.

26. Birch LL (1999) Development of food preferences. Annu Rev Nutr 19, 41-62.

27. Fisk CM, Crozier SR, Inskip HM, et al. (2011) Influences on the quality of young children's diets: the importance of maternal food choices. Br J Nutr 105, 287-296.

28. Rauber F, da Costa Louzada ML, Feldens CA, et al. (2013) Maternal and family characteristics associated with the Healthy Eating Index. J Hum Nutr Diet 26, 369-379.

29. Birch L, Savage JS \& Ventura A (2007) Influences on the development of children's eating behaviours: from infancy to adolescence. Can J Diet Pract Res 68, s1-s56.

30. Story MK \& Karen M (2009) Creating healthy food and eating environments: policy and environmental approaches. Ann Rev Public Health 29, 253-272.

31. Vitolo MR, Bortolini GA, Feldens CA, et al. (2005) [Impact of the 10 steps to healthy feeding in infants: a randomized field triall. Cad Saude Publica 21, 1448-1457.

32. Vitolo MR, Rauber F, Campagnolo PD, et al. (2010) Maternal dietary counseling in the first year of life is associated with a higher healthy eating index in childhood. J Nutr $\mathbf{1 4 0}$, 2002-2007.

33. Kennedy ET, Ohls J, Carlson S, et al. (1995) The Healthy Eating Index: design and applications. J Am Diet Assoc 95, 1103-1108.

34. Brazil Ministry of Health (2005) [Dietary Guidelines for the Brazilian Population]. Brasília: Ministry of Health (Secretaria 
de Atenção à Saúde, Coordenação-Geral da Política de Alimentação e Nutrição).

35. Philippi ST, Latterza AR, Cruz ATR, et al. (1999) [Adapted food pyramid: a guide for a right food choice]. Revista de Nutrição 12, 65-80.

36. Basiotis PP, Carlson A, Gerrior SA, et al. (2002). The Healthy Eating Index: 1999-2000. Washington, DC: US Department of Agriculture, Center for Nutrition Policy and Promotion (CNPP-12). http://www.cnpp.usda.gov/publications/HEI/HEI9900report.pdf (accessed July 2008).

37. Assis MA, Calvo MC, Kupek E, et al. (2010) Qualitative analysis of the diet of a probabilistic sample of schoolchildren from Florianópolis, Santa Catarina State, Brazil, using the Previous Day Food Questionnaire. Cad Saude Publica 26, 1355-1365.

38. Kranz S, Findeis JL \& Shrestha SS (2008) Use of the Revised Children's Diet Quality Index to assess preschooler's diet quality, its sociodemographic predictors, and its association with body weight status. J Pediatr (Rio J) 84, 26-34.

39. Angelopoulos P, Kourlaba G, Kondaki K, et al. (2009) Assessing children's diet quality in Crete based on Healthy Eating Index: the Children Study. Eur J Clin Nutr 63, 964-969.

40. Manios Y, Kourlaba G, Kondaki K, et al. (2009) Diet quality of preschoolers in Greece based on the Healthy Eating Index: the GENESIS study. J Am Diet Assoc 109, 616-623.

41. Briefel RR, Crepinsek MK, Cabili C, et al. (2009) School food environments and practices affect dietary behaviors of US public school children. J Am Diet Assoc 109, Suppl. 2, S91-S107.

42. Birch LL \& Ventura AK (2009) Preventing childhood obesity: what works? Int J Obes (Lond) 33, Suppl. 1, S74-S81.

43. Victora CG, de Onis M, Hallal PC, et al. (2010) Worldwide timing of growth faltering: revisiting implications for interventions. Pediatrics 125, e473-e480.

44. Singer MR, Moore LL, Garrahie EJ, et al. (1995) The tracking of nutrient intake in young children: the Framingham Children's Study. Am J Public Health 85, 1673-1677.

45. Stein AD, Shea S, Basch CE, et al. (1991) Variability and tracking of nutrient intakes of preschool children based on multiple administrations of the 24-hour dietary recall. $A m$ Epidemiol 134, 1427-1437.

46. Zive MM, Berry CC, Sallis JF, et al. (2002) Tracking dietary intake in white and Mexican-American children from age 4 to 12 years. J Am Diet Assoc 102, 683-689.

47. Northstone K \& Emmett PM (2008) Are dietary patterns stable throughout early and mid-childhood? A birth cohort study. Br J Nutr 100, 1069-1076.

48. Fremeaux AE, Hosking J, Metcalf BS, et al. (2011) Consistency of children's dietary choices: annual repeat measures from 5 to 13. Br J Nutr 106, 725-731.

49. Mannino ML, Lee Y, Mitchell DC, et al. (2004) The quality of girls' diets declines and tracks across middle childhood. Int $J$ Behav Nutr Phys Act 1, 5.

50. Feferbaum R, de Abreu LC \& Leone C (2012) Fluid intake patterns: an epidemiological study among children and adolescents in Brazil. BMC Public Health 12, 1005.

51. Leite FH, Oliveira MA, Cremm EC, et al. (2012) Availability of processed foods in the perimeter of public schools in urban. J Pediatr (Rio J) 88, 328-334.

52. Sarno F, Claro RM, Levy RB, et al. (2009) Estimated sodium intake by the Brazilian population, 2002-2003. Rev Saude Publica 43, 219-225.

53. He FJ \& MacGregor GA (2006) Importance of salt in determining blood pressure in children: meta-analysis of controlled trials. Hypertension 48, 861-869.

54. Magriplis E, Farajian P, Pounis GD, et al. (2011) High sodium intake of children through 'hidden' food sources and its association with the Mediterranean diet: the GRECO study. J Hypertens 29, 1069-1076.

55. Weinstein SJ, Vogt TM \& Gerrior SA (2004) Healthy Eating Index scores are associated with blood nutrient concentrations in the third National Health and Nutrition Examination Survey. J Am Diet Assoc 104, 576-584.

56. Hann CS, Rock CL, King I, et al. (2001) Validation of the Healthy Eating Index with use of plasma biomarkers in a clinical sample of women. Am J Clin Nutr 74, 479-486. 